\title{
The Influences of the National Curriculum on Children's Misconceptions about Astronomy and the Use of these Misconceptions in the Development of Interactive Teaching Materials
}

\author{
By John H. Baxter \\ St. Luke's College, Exeter University, Exeter, England
}

It is now well established that children construct their own explanations for the easily observed astronomical events before they receive any formal education in astronomy (see Mali \& Howe, 1985; Nussbaum \& Novak, 1976; Vosnaidou, 1991. It is also generally accepted that childrens notions, or 'alternative frameworks' are tenacious and frequently pass into adulthood (Gunstone et al, 1981). Baxter's (1989) survey revealed a hierarchy of alternative frameworks about astronomy that became less naive as age increases, but also revealed that many pupils leaving school at the age of 16 years did not explain the easily observed astronomical events within a post-Copernican framework.

Until the introduction of a National Curriculum in 1989, astronomy rarely featured in English schools' science curricula (see Lintern-Ball, 1972; Baxter, 1991). Therefore, it is not surprising to discover that many children and adults (Durant, Evans and Thomas, 1989) have concepts about astronomy that bear a closer resemblance to those of the Dark Ages than the 20th-Century space age.

For over six years now astronomy has been an established part of English children's school science experience. The survey reported in this paper was carried out to discover if children's alternative frameworks have been affected by the more widespread teaching of astronomy.

\section{Methods of Investigation}

This study investigated children's ideas about the same four astronomical domains researched in the 1988 survey (see Baxter, 1989):

- Planet Earth in space.

- Day and night.

- Phases of the Moon.

- The seasons.

The study employed the same astronomy conceptual survey instrument developed for the 1988 survey (see Baxter, 1989, for full details of the survey method).

This sample comprised 120 children aged 9 to 10 years - 56 boys and 64 girls - taken from a number of primary schools in the south-west of England, including primary schools used in the original survey. According to the subjective opinions of the class teachers, the pupils covered the full range of abilities normally expected in state primary schools.

\section{Results of the Survey}

For clarity of presentation, the results obtained for a particular domain are followed by a comparison with those obtained during the survey of 1988 . Prevalence trend diagrams are given for each of the domains investigated. The comparisons are made against the 10-16 year age range of the 1988 survey. 


\subsection{Planet Earth and Gravity}

Pupils were asked to imagine that they had taken off in a space rocket and had been travelling away from Earth for one day. They look out of the window towards the Earth. They were then asked to draw how they thought the Earth would look. After completing their drawing, they were asked to draw in some people to show where they could live, then some clouds and then rain falling from the clouds.

The pupil' s drawings fell into four distinct notions and reflected those obtained in the 1988 survey. However, there appears to be a shift away from a naive flat Earth notion and a round Earth with 'UP' being directed towards the North, towards a view that represents - or closely represents - the accepted notion. See Fig. 1.

Only $3 \%$ of the sample in the $1994 / 5$ survey produced flat Earth diagrams. This shows a reduction of $16 \%$ from the $19 \%$ recorded in 1988 . The most notable difference between the diagrams of planet Earth drawn for the two surveys was the change in children's concept of the proportion between the size of the Earth and the height of the clouds. Fifty percent of pupils in the 1988 survey placed the clouds somewhere out in space. Ninety one percent of the diagrams drawn for the 1994 survey placed the clouds close to the Earth. See Fig. 2.

Although there has been a significant improvement in children's concept of planet Earth in space, a Newtonion concept of gravity does not appear to be the prevalent view. However, the consensus view has shifted from the naive notion that North is 'UP' and South 'DOWN', to an intermediate notion that is represented by rain falling towards the centre of the Earth, but with people drawn with their heads pointing towards the North. No diagrams of this type were recorded during the 1988 survey.

\subsection{Day and Night}

Children's ideas about day and night have also shifted away from the more naive notions. None of the 1994 sample believed that it gets dark at night because the Sun goes behind a hill, and only $2 \%$ thought that it gets dark at night because the Moon covers the Sun. This compares with $4 \%$ believing in the influence of hills and $20 \%$ in the Moon making it dark at night as revealed by the 1988 survey. See Fig. 3.

The most significant change in children's explanations for day and night has been their rejection of the belief that either the Sun orbits the Earth, or the Earth orbits the Sun once a day. The 1988 survey revealed that $103 \% \dagger$ of the sample explained the cause of day and night within the terms of these supposed orbits. By 1994 the percentage had reduced to $37 \%$. $77 \%$ percent subscribed to the correct view for day and night. This compares with $34 \%$ recorded in the survey of 1988; an improvement of $43 \%$.

\subsection{Phases of the Moon}

Children's explanations for the cause of the Moon's phases fell into three main types. This was a reduction of two from the five revealed by the 1988 survey. None of the sample considered that either the shadow of the Sun or a planet caused the phases. However, $19 \%$ thought that clouds produced the phases. This is an increase of $2 \%$ from the $17 \%$ revealed by the 1988 survey and it appears to be a notion that has persisted.

The most common explanation for the phases of the Moon recorded by the 1988 survey was that of the Earth's shadow falling on the Moon - $44 \%$ subscribed to this view. By 1994 this had dropped to $17 \%$ and the number giving the correct explanation had risen from $28 \%$ to $48 \%$; an improvement of $20 \%$. See Fig. 4.

f It is interesting that the sum of the percentages subscribing to the various notions for the cause of day and night gives a total greater than $100 \%$. This is caused by some pupils selecting more than one cause for this event and can be considered a measure of their uncertainty about this domain. In 1988 the total percentage subscribing to all possible causes was $161 \%$. In 1994 this had fallen to $116 \%$. 


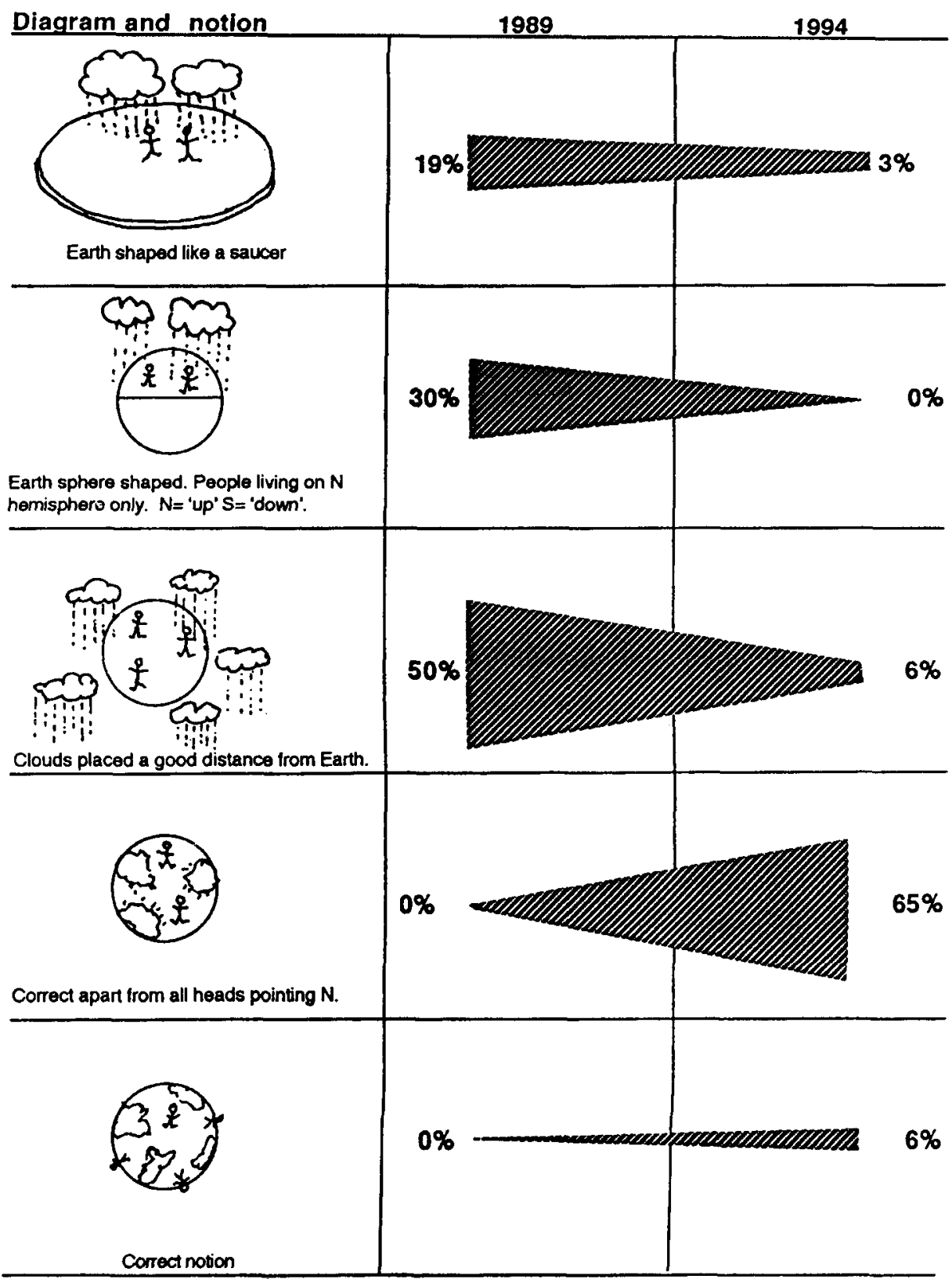

FIGURE 1. Children's changing notions of planet Earth in space.

\subsection{The Seasons}

The changes in children' $s$ notions about the cause of the seasons are almost identical to the conceptual changes that have taken place for the Moon's phases. None of the children from the 1994 sample believed that either a planet took heat from the Sun, or that the Sun moved to the other side of the Earth - 6\% and 7\% respectively subscribed to these notions in 1988 . However, in the same way that children visualised clouds causing the Moon's phases, $9 \%$ of the 1994 sample considered that it gets cold in the winter because clouds take heat away from the Sun. 


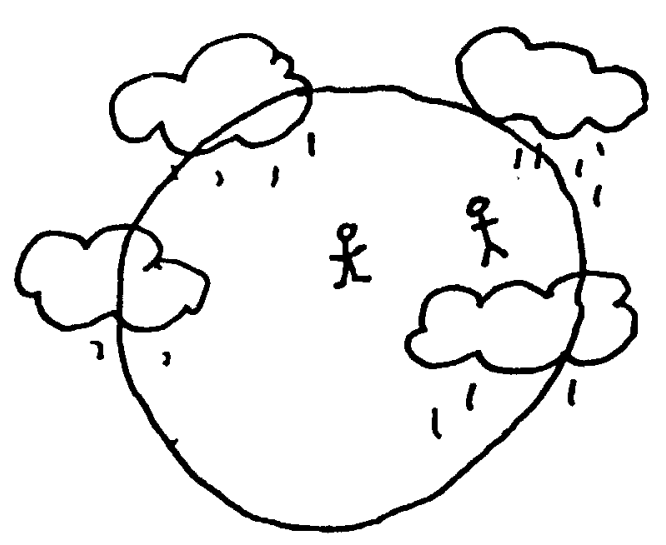

1989

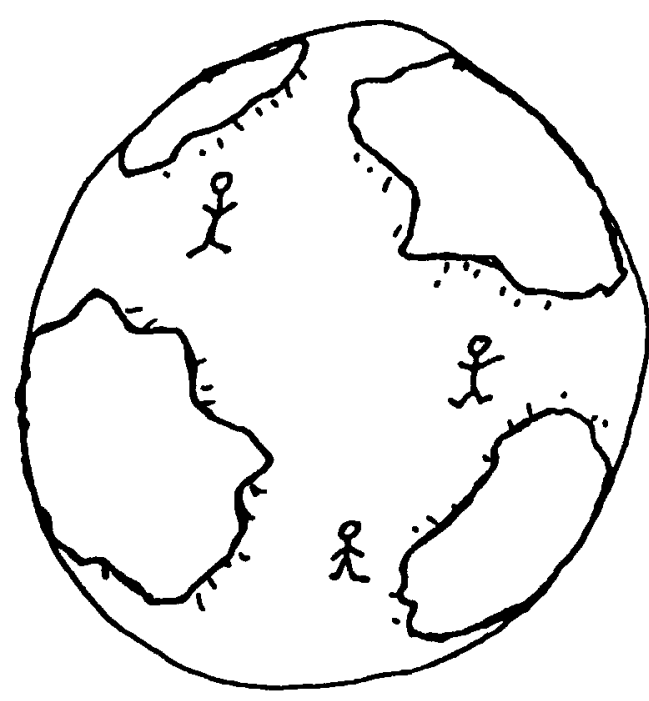

1994

Figure 2. Placing of clouds in 1989 and in 1994.

This is an identical percentage to that obtained during the 1988 survey and this too appears to be a notion that has persisted.

The most common explanation for the cause of the seasons in 1988 was that the Sun moves closer to the Earth during the summer and further away during the winter. $59 \%$ subscribed to this notion in 1988. The number electing this as the cause of the seasons in the 1994 survey fell to $19 \%$, while the correct notion was the most common view with $52 \%$ of the sample giving this reason for the seasons, an improvement of $32 \%$ on the original survey. See Fig. 5.

Although this survey suggests that there has been an improvement in pupils' understanding of the easily observed astronomical events, astronomy has still not taken its place in the mainstream of science. It is still uncommon for pupils to be given an opportunity to develop their science activity skills within the context of astronomy. This is primarily due to a self perpetuating triangle of factors.

The growth of computer generated interactive technology offers a unique opportunity to present pupils with activities that will enable them to develop their science skills within the area of astronomy. However, to date, the field of interactive technologies in education has had a history of being technology led rather than curriculum driven. Our knowledge of alternative notions in astronomy (and in other areas of science) gives a valuable framework for the development of interactive computer programmes because these alternative notions have been shown to be common responses, and to have a common progression pattern. Therefore, if the common responses are used in the design of interactive programmes, such programmes will move away from being the programmer's perception of pupils' knowledge and understanding, towards questions and possible pupil choices that are based on established research.

This means that those researching in the alternative framework movement are not just involved in the collection of pupil's wrong ideas. These misconceptions, and a knowledge of their progression, form a framework for the development of meaningful and well focused computer 


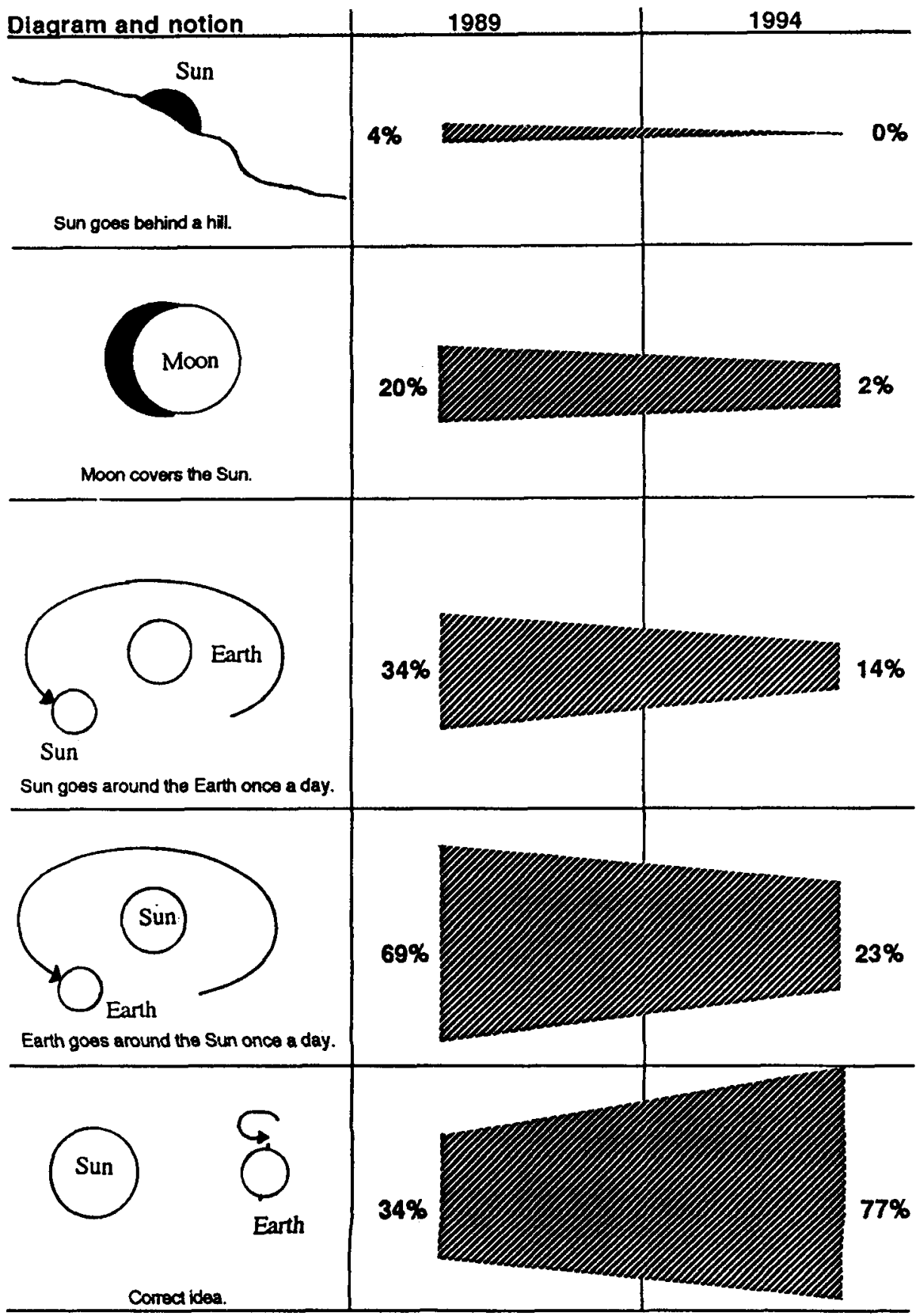

FIGURE 3. Children's changing notions about day and night.

generated interactive materials that are set to become a common feature of education into the next century.

In recognition of the above, a joint research programme has been set up between the University of Exeter and British Telecom (BT) that will develop focused materials for the teaching of astronomy (and other areas in the physical sciences) using our knowledge of pupils alternative 


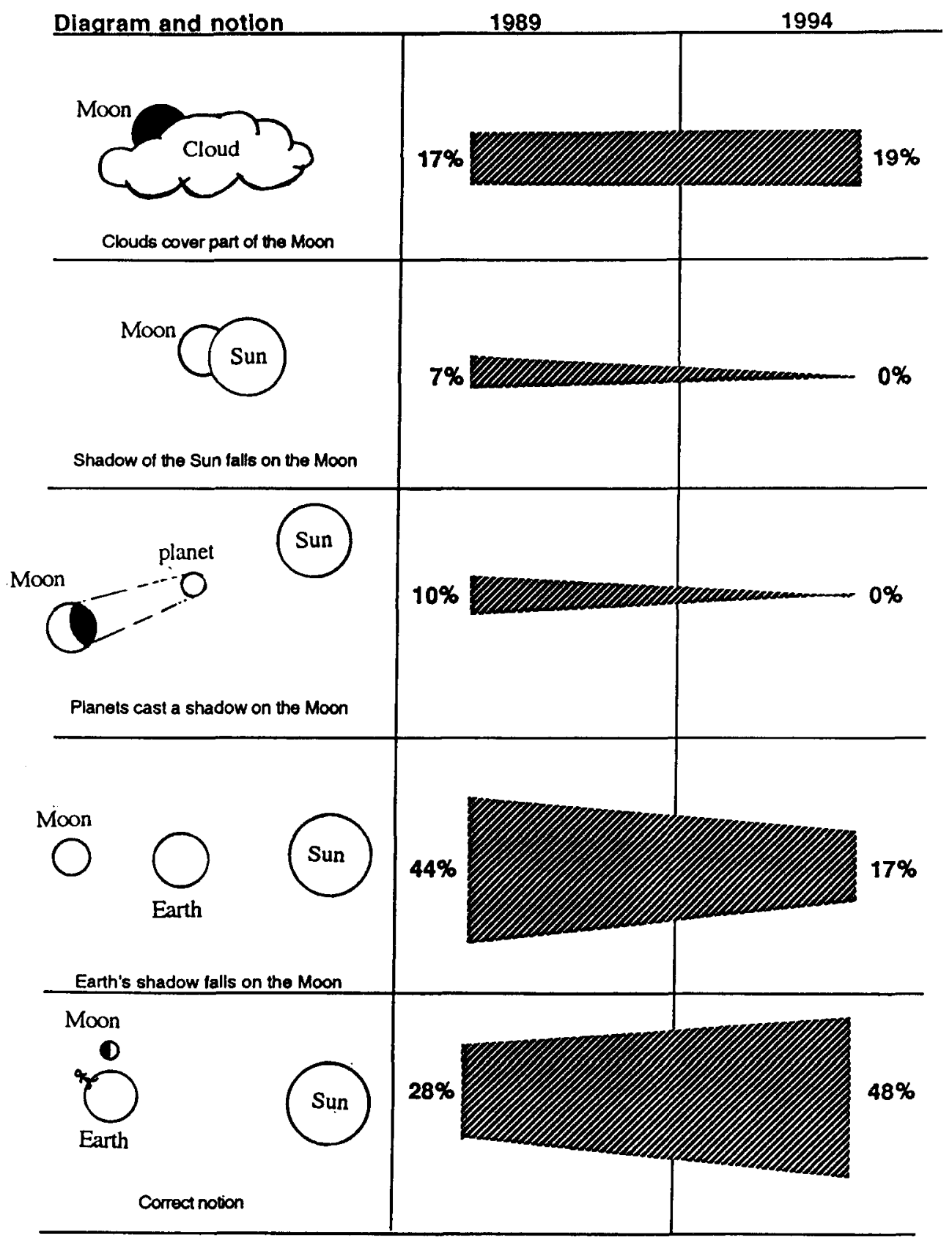

FIGURE 4. Children's changing notions on the phases of the Moon.

notions as a framework. The full range of on-line technologies will be used to distribute these materials, share good teaching practice and deliver online in service training to primary teachers, thereby making a substantial contribution to redressing the shortfall in primary teachers' knowledge (see Mant and Summers, 1993), and giving a unique opportunity to introduce teachers to interactive materials to which they would otherwise not have access, or be able to afford within 


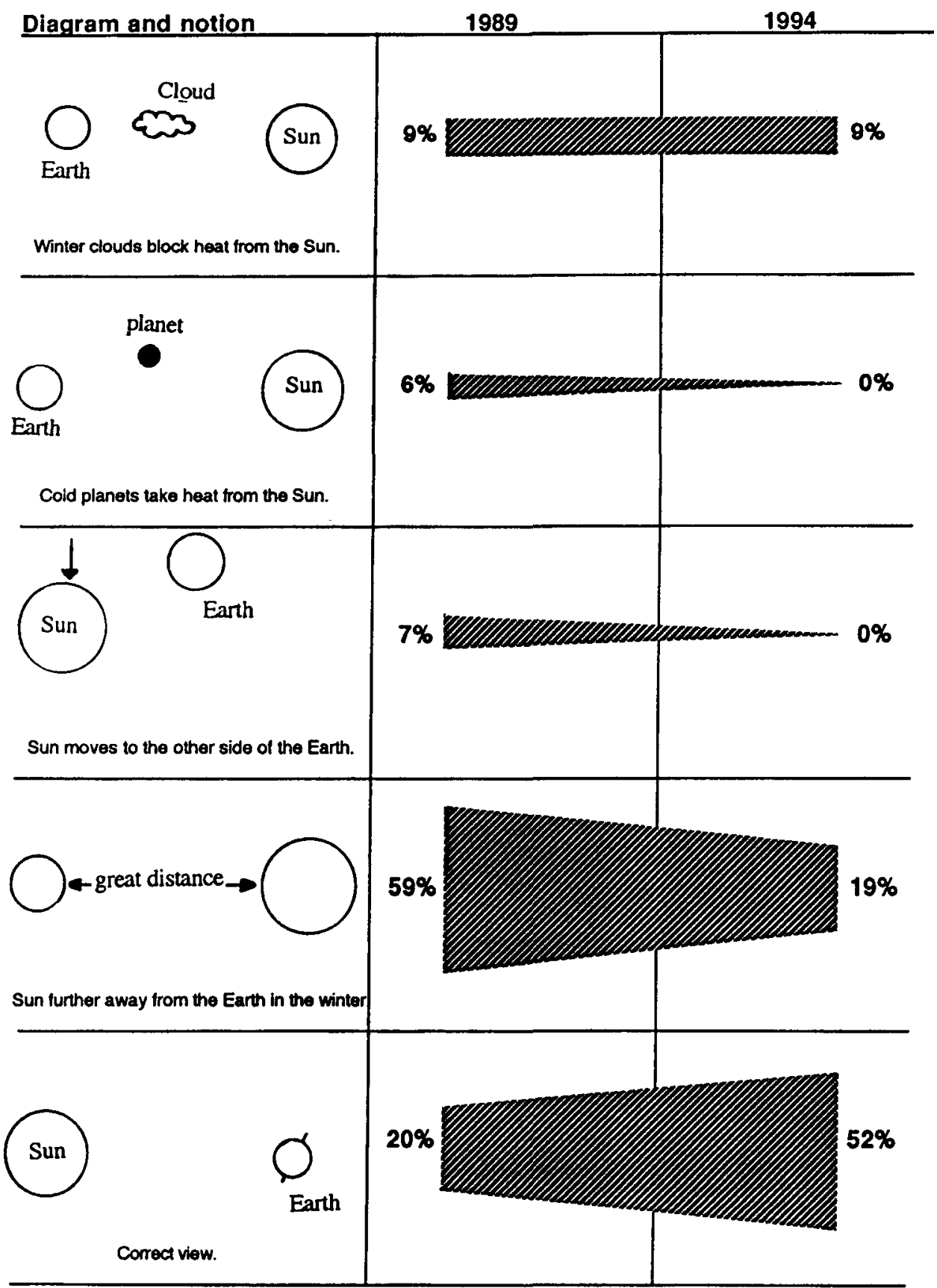

FIGURE 5. Children's changing notions about the seasons.

the ever tightening school budgets. Materials will be accessed on-line via the CampusWorld network and the CampusView server. The participating schools will form a network sharing their good practice via video-conferencing and videotaped lessons. Other schools will be able to access via B.T's CampusView server.

In this way teachers in one school can share their good practice in astronomy education with 
teachers in other distant schools. Pupils will be able to communicate with those in other schools via video-conferencing and $\mathrm{E}$ mail, thereby sharing their ideas and results. In this way well focused astronomy educational material will be produced, distributed and experiences shared, using the full range of on-line technologies now available to schools and colleges.

\section{REFERENCES}

BAXTER, J., 1989, Children's understanding of familiar astronomical events. Int.J.Sci.Educ.11, pp.502-513.

BAXTER, J., 1991, The National Curriculum: a challenge for astronomers. Q.J.R.ast.Soc.32,pp.147157.

Durant,J.R., Evans,G.A. \& Thomas,G.P., 1989, The public understanding of science. Nature. Vol.340 6th. July.

Gunstone, R.F., Champagne,A.B.\& Klopfer,L.E., 1981, Instruction for understanding: a case study. Aust.Sci.Teach.J.27,(3),pp.27-32.

LINTERN-BALL,R.W., 1972, England's astronomical education? Q.J.R.ast.Soc., 13,p486.

MALI,J. \& HowE,A., 1979, Development of Earth and gravity concepts among Nepali children. Science Education, Vol.63,No.5,pp.685-691.

MANT,J. \& Summers, M., 1993, Some primary-school teachers' understanding of the Earth's place in the Universe. Research Papers in Education, Vol.8,No.1.

Nussbaum,J. \& Novak,J.D., 1976, An assessment of children's concepts of the Earth utilising structured interviews. Science Education, Vol.60, No.4,pp.535-550.

SADLER,P., 1987, Misconceptions in astronomy. In: Proceedings of the 2nd. Int. Seminar on Misconceptions \& Educational Strategies in Science \& Maths, Vol.III,pp.422-425. Ithaca, New York: Cornell University Press.

VosnaDoU,S., 1991, Designing curricula for conceptual restructuring: lessons from the study of knowledge acquisition in astronomy. J. of Curriculum Studies,23,pp.219-221. 